\title{
EULAR/ACR Classification Criteria for Adult and Juvenile Idiopathic Inflammatory Myopathies and their Major Subgroups
}

\author{
Ingrid E Lundberg ${ }^{1}$, Anna Tjärnlund ${ }^{1,{ }^{*}, \text { Matteo Bottai }}{ }^{2, *}$, Victoria P Werth ${ }^{3}$, Clarissa \\ Pilkington $^{4}$, Marianne de Visser ${ }^{5}$, Lars Alfredsson ${ }^{2}$, Anthony A Amato ${ }^{6}$, Richard J Barohn ${ }^{7}$, \\ Matthew H Liang ${ }^{8}$, Jasvinder A Singh ${ }^{9}$, Rohit Aggarwal ${ }^{10}$, Snjolaug Arnardottir ${ }^{11}$, Hector \\ Chinoy $^{12}$, Robert G Cooper ${ }^{13}$, Katalin Dankó ${ }^{14}$, Mazen M Dimachkie ${ }^{7}$, Brian M Feldman ${ }^{15}$, \\ Ignacio Garcia-De La Torre ${ }^{16}$, Patrick Gordon ${ }^{17}$, Taichi Hayashi ${ }^{18}$, James D Katz ${ }^{19}$, Hitoshi \\ Kohsaka ${ }^{20}$, Peter A Lachenbruch ${ }^{21}$, Bianca A Lang ${ }^{22}$, Yuhui $\mathbf{L i}^{23}$, Chester V Oddis ${ }^{10}$, \\ Marzena Olesinska ${ }^{24}$, Ann M Reed ${ }^{25}$, Lidia Rutkowska-Sak ${ }^{26}$, Helga Sanner ${ }^{27}$, Albert Selva- \\ O'Callaghan ${ }^{28}$, Yeong Wook Song ${ }^{29}$, Jiri Vencovsky ${ }^{30}$, Steven R Ytterberg ${ }^{31}$, Frederick W \\ Miller ${ }^{32, \S}$, Lisa G Rider ${ }^{32, \S}$, the International Myositis Classification Criteria Project \\ consortium $^{\dagger}$, the Euromyositis register ${ }^{\dagger}$, and the Juvenile dermatomyositis cohort \\ biomarker study and repository (JDRG) (United Kingdom and Ireland) ${ }^{\dagger}$
}

\begin{abstract}
${ }^{1}$ Rheumatology Unit, Department of Medicine, Karolinska University Hospital, Solna, Karolinska Institutet, Stockholm, Sweden ${ }^{2}$ Institute for Environmental Medicine, Karolinska Institutet, Stockholm, Sweden ${ }^{3}$ Department of Dermatology, Philadelphia VAMC and Hospital of the University of Pennsylvania, Philadelphia, USA ${ }^{4}$ Department of Rheumatology, Great Ormond Street Hospital for Children NHS Trust, London, United Kingdom ${ }^{5}$ Department of Neurology, Academic Medical Centre, Amsterdam, Netherlands ${ }^{6}$ Department of Neurology, Brigham and Women's Hospital, Harvard Medical School, Boston, USA ${ }^{7}$ Department of Neurology, University of Kansas Medical Center, Kansas City, USA ${ }^{8}$ Division of Rheumatology, Immunology and Allergy, Brigham and Women's Hospital, and Section of Rheumatology, Boston VA Healthcare, Boston, USA 9 University of Alabama and Birmingham VA Medical Center, Birmingham, USA \& Mayo Clinic College of Medicine, Rochester, USA ${ }^{10}$ Division of Rheumatology and Clinical Rheumatology, University of Pittsburgh School of Medicine, Pittsburgh, USA ${ }^{11}$ Department of Clinical Neuroscience, Karolinska Institutet, Stockholm, Sweden ${ }^{12}$ National Institute of Health
\end{abstract}

\footnotetext{
Corresponding author: Ingrid E. Lundberg, Rheumatology Unit, D2:01, Karolinska University Hospital, Solna, S-171 76 Stockholm, Sweden, Ingrid.Lundberg@ki.se, Telephone number: +46 851776087.

Contributed equally

$\S_{\text {Contributed equally }}$

see Appendix

Contributor statement

All authors were involved in drafting the article or revising it critically for important intellectual content and approved the final version to be published. All authors had full access to all of the data in the study and take responsibility for the integrity of the data and the accuracy of the data analysis.

Study conception and design

IEL, AT, MB, VPW, CP, MdV, LA, AAA, RJB, MHL, JAS, KD, BMF, HK, PAL, BAL, FWM, LGR

Acquisition of data

IEL, AT, MB, VPW, CP, MdV, LA, AAA, RJB, MHL, JAS, RA, SA, HC, RGC, KD, MMD, BMF, IG-DLT, PG, TH, JDK, HK, PAL,

BAL, YL, CVO, MO, AMR, LR-S, HS, AS-O, YWS, JV, SRY, FWM, LGR, The International Myositis Classification Criteria

Consortium, working committee members.

Analysis and interpretation of data

IEL, AT, MB, VPW, CP, MdV, LA, AAA, RJB, MHL, JAS, RA, BMF, IG-DLT, PG, HK, PAL, BAL, YL, FWM, LGR
} 
Research Manchester Musculoskeletal Biomedical Research Unit, Central Manchester University Hospitals NHS Foundation Trust, University of Manchester, Manchester, United Kingdom ${ }^{13} \mathrm{MRC} /$ ARUK Institute of Ageing and Chronic Disease, Faculty of Health \& Life Sciences, University of Liverpool, Liverpool, United Kingdom ${ }^{14}$ Division of Immunology, 3rd Department of Internal Medicine, Medical and Health Science Center, University of Debrecen, Debrecen, Hungary ${ }^{15}$ Division of Rheumatology, Department of Pediatrics, University of Toronto and The Hospital for Sick Children, Toronto, Canada ${ }^{16}$ Department of Immunology and Rheumatology, Hospital General de Occidente, Secretaría de Salud, and University of Guadalajara, Guadalajara, Jalisco, México ${ }^{17}$ Department of Rheumatology, King`s College Hospital NHS Foundation Trust, London, United Kingdom ${ }^{18}$ Clinical Immunology, Doctoral Program in Clinical Sciences, Graduate School of Comprehensive Human Sciences, University of Tsukuba, Tsukuba, Japan ${ }^{19}$ National Institute of Arthritis and Musculoskeletal and Skin Diseases, National Institutes of Health, US Department of Health and Human Services, Bethesda, USA ${ }^{20}$ Department of Rheumatology, Graduate School of Medical and Dental Sciences, Tokyo Medical and Dental University, Tokyo, Japan ${ }^{21}$ Department of Public Health, Oregon State University, Corvallis, USA ${ }^{22}$ Division of Rheumatology, Department of Pediatrics, IWK Health Centre and Dalhousie University, Halifax, Canada ${ }^{23}$ Department of Rheumatology and Immunology, People's Hospital of Beijing University, Beijing, China ${ }^{24}$ Connective Tissue Diseases Department, National Institute of Geriatrics, Rheumatology and Rehabilitation, Warsaw, Poland ${ }^{25}$ Department of Pediatrics, Duke University, Durham, USA ${ }^{26}$ Paediatric Clinic of Rheumatology, Institute of Rheumatology, Warsaw, Poland ${ }^{27}$ Section of Rheumatology, Oslo University Hospital-Rikshospitalet, Oslo, Norway ${ }^{28}$ Vall d'Hebron General Hospital, Barcelona, Spain ${ }^{29}$ Department of Internal Medicine, Medical Research Center, Clinical Research Institute, Seoul National University College of Medicine, Seoul, Republic of Korea ${ }^{30}$ Institute of Rheumatology and Department of Rheumatology, 1st Faculty of Medicine, Charles University, Prague, Czech Republic ${ }^{31}$ Division of Rheumatology, Mayo Clinic College of Medicine, Rochester, USA ${ }^{32}$ Environmental Autoimmunity Group, Clinical Research Branch, National Institute of Environmental Health Sciences, National Institutes of Health, US Department of Health and Human Services, Bethesda, USA

\section{Abstract}

Objective-To develop and validate new classification criteria for adult and juvenile idiopathic inflammatory myopathies (IIM) and their major subgroups.

Methods-Candidate variables were assembled from published criteria and expert opinion using consensus methodology. Data were collected from 47 rheumatology, dermatology, neurology and pediatric clinics worldwide. Several statistical methods were utilized to derive the classification criteria.

Results-Based on data from 976 IIM patients (74\% adults; $26 \%$ children) and 624 non-IIM patients with mimicking conditions (82\% adults; $18 \%$ children) new criteria were derived. Each item is assigned a weighted score. The total score corresponds to a probability of having IIM. Subclassification is performed using a classification tree. A probability cutoff of 55\%, corresponding to a score of 5.5 (6.7 with muscle biopsy) "probable IIM", had best sensitivity/specificity (87\%/82\% without biopsies, $93 \% / 88 \%$ with biopsies) and is recommended as a minimum to 
classify a patient as having IIM. A probability of $\geq 90 \%$, corresponding to a score of $\geq 7.5$ ( $\geq 8.7$ with muscle biopsy), corresponds to "definite IIM". A probability of $<50 \%$, corresponding to a score of $<5.3$ ( $<6.5$ with muscle biopsy) rules out IIM, leaving a probability of 250 to $<55 \%$ as "possible IIM".

Conclusions-The EULAR/ACR classification criteria for IIM have been endorsed by international rheumatology, dermatology, neurology and pediatric groups. They employ easily accessible and operationally defined elements, and have been partially validated. They allow classification of "definite", "probable", and "possible" IIM, in addition to the major subgroups of IIM, including juvenile IIM. They generally perform better than existing criteria.

\section{Keywords}

Dermatomyositis; Polymyositis; Autoimmune diseases

\section{Introduction}

Idiopathic inflammatory myopathies (IIM), collectively known as myositis, are heterogeneous disorders characterized by muscle weakness and muscle inflammation [1]. The most common subgroups in adults are dermatomyositis (DM), polymyositis (PM), and inclusion body myositis (IBM) [2], and in children, juvenile DM (JDM).

The International Myositis Assessment and Clinical Studies Group (IMACS) has developed consensus on outcome measures and definitions of improvement to be used in clinical trials for myositis [3, 4]. A prerequisite for clinical trials and other clinical studies is the inclusion of well-defined patient groups. A wide variety of diagnostic or classification criteria for myositis are used [2, 5-16], but are generally derived empirically and not validated. The criteria of Bohan and Peter [7, 8] are most widely used, but have limitations. Because they do not clearly specify how to exclude other forms of myopathy, they may misclassify IBM patients as PM [13, 17-19], and muscular dystrophies with inflammation as myositis, and each criterion is not defined explicitly. New discoveries in the last decade, such as myositisspecific autoantibodies, that are associated with distinct clinical phenotypes [2, 20-22], may provide opportunities to improve the precision of classification, but have not been tested adequately $[11,23]$.

The aim of this project was to develop classification criteria for adult and juvenile IIM. The specific goal was to define the minimum essential, easily available clinical and laboratory features to: (i) distinguish IIM from mimicking conditions with high sensitivity and specificity, and (ii) distinguish the major subgroups of IIM.

\section{Methods}

\section{Study design}

The International Myositis Classification Criteria Project (IMCCP), an international collaboration with experts from adult and pediatric rheumatology, neurology, dermatology, epidemiology, and biostatistics was established in 2004 and followed at our best the EULAR and ACR recommendations for development of classification criteria from that time or 
published soon thereafter [24, 25]. A steering committee (Supplementary 1) and a larger working committee with experts in IIM were formed (See Appendix).

Using the nominal group technique experts in IIM from the steering committee and the working committee [26-29] designed the study and validation experiments, assembled and defined candidate criteria from published myositis criteria [2, 5-16] and other characteristics of myositis, determined and assembled the IIM subgroup diagnoses and comparator conditions that were studied. A pilot study to assess the practicality of capturing the items showed a fair agreement of data availability from IIM and non-IIM cases (Supplementary 2). Input was obtained from myositis experts, by email to the IMACS network and requesting comments on the items, to maximize face and content validity [24, 25]. The steering committee revised the list of variables based on the comments and further suggestions from the IMACS network and 93 variables (Supplementary 3) were selected by the steering committee for study in cases and comparators. A glossary and definitions were developed according to an ACR glossary [30, 31] (Supplementary 4). Data were abstracted from patients' records and entered into a web-based database.

Inclusion criteria for cases and comparators were: i) diagnosis for at least 6 months prior to study inclusion; ii) physician certainty of diagnosis - either known IIM or, as comparators, known non-IIM cases where myositis was considered in the initial differential diagnosis; iii) patients with the most recent and complete data were prioritized to acquire the most complete data in a consistent manner. A maximum of 40 cases and an equal number of comparators were collected from each center.

The study was approved by ethics committees at each site.

\section{Data analysis and candidate criteria selection}

The association of each variable with the diagnosis (IIM, non-IIM) was assessed by odds ratios and tested with the Fisher's exact test. The treating physician diagnosis was considered the gold standard for analysis. Three classification techniques were explored: (i) a sum-of-items model in which a patient was classified as a case if the patient had a specified number of items from a set of items; (ii) a probability-score model; and (iii) a classification tree. The ensuing candidate criteria were examined with respect to statistical performance and clinical relevance. Due to the observed superior discriminating performance of the probability-score model, the other models were set aside.

\section{Criteria development}

The probability-score model summed score points associated with the signs and symptoms present. The score points were obtained as coefficients of a logistic regression model used to combine multiple variables for predicting IIM. The statistical significance of the resulting increase in the goodness-of-fit of the model was assessed using the Wald test. The improvement in predictive ability was measured by the increment in specificity and sensitivity and summarized by the area under the receiver operating characteristic curve (AUC). 
Pediatric experts are using fewer muscle biopsies for classification of JDM in clinical practice than adult rheumatologists. Thus, a second model not including biopsy variables was developed. Assessment of statistical performance for each score/probability cutoff value provided the basis for a recommendation of a cutoff value for IIM classification by the steering committee. The proposed cutoffs were then defined as possible, probable and definite IIM. To facilitate use of the new criteria, a web-based calculator for the probabilityscore model was developed.

The new classification criteria were compared to previous IIM criteria. Their statistical performance was calculated and number of patients per IIM sub-diagnosis classified as IIM by the different criteria sets.

To distinguish subgroups of patients classified with IIM according to the new criteria a classification tree was developed. The tree was based on the variables in the new classification criteria, statistical analyses, as described in a separate methodology paper and on expert opinion.

\section{Validation}

The new criteria were internally cross-validated. Samples of equal size to the original sample were drawn from the entire population at random with replacement, so-called "bootstrap" samples [32]. The bootstrap sample represented the training sample, and the remaining subjects not contained in the bootstrap sample constituted the validation sample. The probability score was applied to each bootstrap training sample separately and then utilized to predict IIM in the validation sample. The procedure was repeated in over 200 bootstrap samples, and the average AUC was calculated.

The performance of the new criteria for IIM including the subgroups was tested for sensitivity in two independent cohorts, the Euromyositis Register (https://euromyositis.eu/) and the Juvenile Dermatomyositis Cohort Biomarker Study and Repository (JDRG) (UK and Ireland) (https://www.juveniledermatomyositis.org.uk/).

The program Stata v13 (StatCorp, College Station, TX, USA) was used for data management and statistical analyses. The statistical program R (R Core Team (2014). R: A language and environment for statistical computing. R Foundation for Statistical Computing, Vienna, Austria. URL http://www.R-project.org/) was utilized for some analyses.

A report detailing the methodology will be submitted as a separate publication (manuscript submitted).

\section{Results}

\section{Study population}

Data from 976 IIM patients ( $74.5 \%$ adults; $25.5 \%$ children) (Table 1) were collected between 2008 and 2011 from 23 European, 17 North American, one South American, and six Asian sites, representing IIM subgroups of: JDM ( $n=248)$, PM ( $n=245), D M(n=239)$, IBM ( $\mathrm{n}=176)$, amyopathic DM (ADM) $(\mathrm{n}=44)$, hypomyopathic DM $(\mathrm{n}=12)$, immune- 
mediated necrotizing myopathy (IMNM) $(n=11)$ and juvenile PM $(n=1)$. A total of 624 comparators (81.6\% adults; $18.4 \%$ children) (Table 1) representing a broad spectrum of conditions that can mimic IIM were included, comprising systemic inflammatory diseases (36.5\%), muscle dystrophies (16.0\%), drug- or toxin-associated myopathies (7.9\%), motor neuron diseases/neuropathies (7.7\%), metabolic myopathies (6.9\%), myalgias (4.5\%), dermatologic diseases (3.7\%), endocrine myopathies (3.7\%), infectious myopathies (4.5\%), mitochondrial myopathies (2.4\%), neuromuscular diseases (2.6\%), other myopathies (1.9\%), immune-mediated skin conditions (0.5\%), as well as other diagnoses (1.3\%) (Supplementary $5,6)$.

\section{Candidate criteria selection and criteria development}

Based on statistical models, 16 variables from six categories best distinguished IIM cases from comparators (Table 2) and each variable was assigned a weight (score) based on its influence to discriminate IIM from non-IIM. A total score was computed by adding score points corresponding to each criterion being present. The score can be converted into a probability of IIM (Figure 1A, B) by:

Probability of IIM including muscle biopsy=1/[1+exponential(5.33-score $)]$

or,

Probability of IIM without muscle biopsy=1/[1+exponential $(6.49-$ score $)]$

or by utilizing the online web-calculator (www.imm.ki.se/biostatistics/calculators/iim). Sensitivity and specificity for varying probability cutoffs are shown in Figure 1 (C, D).

\section{Cut-points for classification}

The best balance between sensitivity and specificity was found for a probability of 55-60\% for the criteria not including muscle biopsy data, and 55-75\% when including muscle biopsies, or a total aggregated score of score of $\geq 5.5$ and $\leq 5.7$ ( $\geq 6.7$ and $\leq 7.6$ if biopsy is available). The IMCCP proposes that a patient may be classified as IIM if the probability exceeds a predetermined cutoff of at least 55\% (corresponding to a score of 25.5 , or $\geq 6.7$ if biopsies are included) based on maximization of statistical performance and best balance between sensitivity and specificity. The level of probability $255 \%$ and $<90 \%$ was defined as "probable IIM". The Steering committee recommends, based on expert opinion, that "definite IIM" should equal a probability of $\searrow 90 \%$, corresponding to having total aggregate score of $\geq 7.5$ without muscle biopsy and $\geq 8.7$ with muscle biopsy.

Patients falling in the probability range $250 \%$ and $<55 \%$ will be classified as "possible IIM". For a patient to be classified as a non-IIM patient the probability would have to be $<50 \%$ (score of maximum 5.3 without biopsies; 6.5 with biopsies).

As suggested by pediatric experts and dermatologists, for patients with pathognomonic skin rashes of DM or JDM, classification criteria were developed which did not include muscle biopsy data (Table 2). However, where no skin rash is present, a muscle biopsy is required 
for diagnosis, as determined by a consensus of expert opinion within the IMCCP steering and working committees. Both sets apply equally well to adult IIM patients and to juvenile dermatomyositis patients and should be used when IIM is suspected and no better explanation for the symptoms exists, as agreed upon by expert opinion. Definitions for the criteria items are presented in table 2 .

\section{Identification of subgroups}

A patient classified with IIM by the EULAR/ACR classification criteria (probability of IIM $255 \%$ ) can be further sub-classified with a classification tree (Figure 2). Age at onset of first symptom ( $\geq 18$ years of age) distinguishes adult from juvenile IIM. Thereafter, clinical findings and muscle biopsy features sub-classify adult IIM patients into PM, IBM, ADM or DM. Based on our data set juvenile patients with skin rash can be classified into JDM. Three subgroups cannot be further separated using our criteria because of small sample sizes: juvenile PM, IMNM, and hypomyopathic DM.

Among patients with IIM by the EULAR/ACR classification criteria (probability of IIM $255 \%$ ), and with sufficient data to allow sub-classification ( $n=703)$, the number of cases in the subgroups as defined according to the classification tree was enumerated (Table 3 ). The agreement between the classification tree subgroups and the physician-diagnosed subgroups in the dataset was high (92.6\% agreement, kappa $=0.90, \mathrm{p}<0.00001)$. The agreement proportions, with a probability of 55\%, were 1.00 for JDM, 0.89 for DM, 0.94 for ADM, 0.92 for IBM, and 0.93 for PM. Raising the probability cutoff of IIM to $90 \%$ yielded $94.9 \%$ agreement, kappa $=0.93, \mathrm{p}<0.00001$. With a probability cutoff of $90 \%$ the agreement proportions were 1.00 for JDM, 0.96 for DM, 0.95 for ADM, 0.93for IBM, and 0.88 for PM.

\section{Performance of EULAR/ACR criteria compared to published criteria}

Performance of the EULAR/ACR criteria was compared to published criteria for IIM $[7,8,10,11,14,15]$ using the IMCCP dataset (Table 4$)$. The new criteria including muscle biopsy features displayed high sensitivity (93\%) and specificity (88\%). There was slightly lower performance without biopsy variables (sensitivity and specificity $87 \%$ and $82 \%$, respectively). Among the assessed criteria, the Targoff criteria [11] showed the highest sensitivity (93\%) and specificity (89\%). Other criteria had either high sensitivity and low specificity (Bohan and Peter [7,8] and Tanimoto criteria [10]), or low sensitivity and high specificity (Dalakas and Hohlfeld [14] and ENMC criteria [15]).

We studied how different criteria could classify patients with diverse IIM sub-diagnoses in the IMCCP dataset (table 4). The EULAR/ACR classification criteria correctly classified most patients with all IIM sub-diagnoses. When biopsy data were used, the performance improved for IBM (94\% with biopsy data vs. 58\% without biopsy data) and PM (86\% with biopsy data vs. 79\% without biopsy data). The Bohan and Peter [7, 8], Tanimoto [10] and Targoff [11] criteria correctly classified all IIM sub-diagnoses except ADM, a diagnosis not included in those criteria. The Dalakas and Hohlfeld criteria [14] could not classify any subdiagnoses. The ENMC criteria [15] correctly classified DM and JDM cases but no other subdiagnoses. 
A comparison between the EULAR/ACR classification criteria (55\% probability cutoff) and the Bohan and Peter criteria [7, 8] showed 89\% agreement (kappa $=0.71, \mathrm{p}<0.00001$ ) without including muscle biopsy data, and $93 \%$ agreement (kappa $=0.73, \mathrm{p}<0.00001)$ using muscle biopsy findings. Comparison between the newly-developed criteria and the Targoff criteria [11] demonstrated that the agreement was $89 \%$ (kappa $=0.74, \mathrm{p}<0.00001)$ and $93 \%$ (kappa $=0.82, \mathrm{p}<0.00001$ ) without or with inclusion of muscle biopsy data, respectively.

\section{Validation}

Internal validation-Using the criteria without muscle biopsy data, 733 observations were used, resulting in $\mathrm{AUC}=0.942$ and cross-validated area $=0.933$. Using the criteria with muscle biopsy data, 507 observations were included, resulting in AUC $=0.962$ and crossvalidated area $=0.942$.

External validation for sensitivity-Data from 592 cases $(\mathrm{PM}=281, \mathrm{DM}=256$, $\mathrm{IBM}=33, \mathrm{JDM}=18$ and $\mathrm{ADM}=4$ ) in the Euromyositis register were used where clinical, laboratory and muscle biopsy data were available (Karolinska University Hospital, Stockholm, Sweden; Prague Hospital, Prague, Czech Republic; Oslo University Hospital, Oslo, Norway) (Supplementary 7). When there was sufficient information available, the EULAR/ACR classification criteria confirmed IIM diagnosis using a 55\% probability cutoff for classification of IIM with no misclassification, yielding $100 \%$ sensitivity. Using the criteria without muscle biopsies, 489 (83\%) patients were classified as IIM, and 103 (17\%) patients could not be classified due to missing data. For the criteria with biopsies, 204 (34\%) were classified as IIM and 388 (66\%) could not be classified due to missing muscle biopsy data in the register. Results for the IBM and PM subgroups improved when biopsy data were included: $97 \%$ of IBM cases could be classified compared to $73 \%$ when biopsy data were not included. For PM, $80 \%$ and $76 \%$ respectively could be classified. Raising the IIM classification cutoff from $55 \%$ to $90 \%$ decreased the total number of cases that could be classified to only $63 \%$ (not including muscle biopsies) or $28 \%$ (including muscle biopsies) due to absence of some muscle biopsy variables in the Euromyositis registry data-base.

The Juvenile Dermatomyositis Biomarker Study and Repository (UK and Ireland): The JDRG register included 332 juvenile IIM cases in the study (definite JDM=292, probable $\mathrm{JDM}=20$, definite juvenile $\mathrm{PM}=4$, probable juvenile $\mathrm{PM}=2$, focal myositis $=6$ and other IIM=8) (Supplementary 8). Muscle biopsy data were not available for all, thus the EULAR/ACR classification criteria without muscle biopsy data were used to test sensitivity in this dataset. Three hundred and seven (92\%) cases could be classified using the 55\% cutoff and no case was misclassified, yielding $100 \%$ sensitivity. The remaining 25 cases (8\%) could not be classified due to missing data. Raising the cutoff stepwise to $60 \%, 70 \%$, $80 \%$ or $90 \%$ yielded classification of $92 \%, 88 \%, 87 \%$ or $64 \%$ cases respectively, where classification was possible.

\section{Web-calculator}

A web-calculator was developed (www.imm.ki.se/biostatistics/calculators/iim) as an aid to use the EULAR/ACR classification criteria. A probability range of classification can be obtained, providing the minimum and maximum probability. In addition to the probabilities 
acquired, the aggregated scores will be displayed. Whenever sufficient data are entered, the sub-classification will be displayed.

\section{Discussion}

Classification criteria are essential for inclusion of comparable patients in studies. No validated classification criteria for IIM currently exist. The EULAR/ACR classification criteria for IIM offer advantages that previous criteria lack. They are data-driven, exhibit high sensitivity and specificity, and use a limited number of accessible, defined clinical and laboratory variables. Internal validation and testing in external cohorts confirmed excellent performance. Importantly, the new criteria capture the most frequent IIM subgroups and can be used for both adults and children for research studies and clinical trials.

The new EULAR/ACR classification criteria provide a score with a corresponding probability of having IIM. This provides investigators flexibility in inclusion criteria for different types of studies, e.g. clinical trials requiring high specificity would warrant a high probability of IIM in the inclusion criteria, whereas epidemiological studies requiring high sensitivity would need inclusion criteria with lower probability of IIM.

The new criteria are based on data from children and adults with different ethnicities from centers in Europe, America and Asia, and use symptoms, signs and other measures that are routinely assessed. A limitation is still that a majority of the patients were Caucasian, and even though we enrolled data from 298 patients from Asia we cannot exclude that there can be differences in manifestations between different ethnical groups, hence we still need to validate the criteria in Asian and African populations. Importantly, in patients with a typical DM skin rash, the criteria can be used without muscle biopsy data. For JDM, 97\% of patients were correctly classified using the new criteria without muscle biopsy data. The new criteria also offer practical advantages in the number of variables needed to be tested. If a sufficient probability is reached, there is no requirement to test all items. Each criterion is well-defined, lessening the opportunities for ad hoc interpretation. The skin rash typical of DM contributed with high weights in the probability score. Skin biopsy is recommended in the absence of muscle symptoms [33, 34]. The EULAR/ACR classification criteria are the first myositis criteria to be validated and tested for sensitivity in other cohorts and revealed no misclassification.

Compared to most previous criteria, the new criteria are superior in sensitivity, specificity and classification accuracy. Classification criteria should have high sensitivity and specificity. The EULAR/ACR criteria demonstrated sensitivity and specificity of $87 \%$ and $82 \%$ respectively, with even higher accuracy when muscle biopsies were included, $93 \%$ and $88 \%$ respectively. Correctly classified patients were $86 \%$ and $91 \%$ respectively with and without inclusion of biopsies, and the criteria performed equally well for adult and juvenile cases. The Targoff criteria [11] also showed good statistical properties, but were not able to capture all subgroups of IIM as ADM patients were not included. Furthermore, the variables were not clearly defined in the Targoff criteria, and testing of more variables is required, including electromyography, which is not always easily accessible and may be painful for patients. Importantly, the EULAR/ACR criteria can be applied to myositis patients with 
overlap diagnoses, such as mixed connective tissue disease or systemic lupus erythematosus with myositis, since these patients were included among IIM cases.

There are limitations of the study; no controls or comparators were included in the external validation cohort, since the IMCCP study was designed before those recommendations from ACR/EULAR were in place, requiring future validation. A validation study using comparators are underway, but we encourage additional validation studies in different populations. Another limitation largely unavoidable in observational data is the high frequency of missing data in the derivation dataset and validation samples, reflecting differences in practice patterns in evaluating patients. Nevertheless, $80 \%$ of cases and comparators had muscle biopsy data available, whereas magnetic resonance imaging data and electromyography were only available for $38 \%$ and $29 \%$ of cases respectively, reflecting their limited usage in clinical. However, magnetic resonance imaging data and electromyography examination are still important for diagnostic purposes of IIM. Patients studied had to have their disease for at least 6 months, which did not allow us to study newonset patients. Importantly, these criteria are proposed as classification criteria in research and in clinical trials, not as diagnostic criteria [35]. There is also some possibility that the cut-points established for probable and definite myositis will need adjustment when tested with new populations of patients.

It took almost 10 years to assemble sufficient numbers of patients with these rare diseases and three subgroups did not have enough subjects to study adequately. During this period a new IIM subgroup became recognized, IMNM [36], of which only a few cases were included into the study. IMNM cases could thus not be distinguished from PM in the subclassification tree. Another subgroup with few cases was juvenile PM, making a dataderived distinction from JDM impossible. However, pediatric rheumatology experts in the IMCCP recommended that the adult sub-classification of IIM could be used for juvenile PM by extrapolation (Figure 2). IBM cases were identified in the sub-classification tree by the clinical features of finger flexor weakness and no response to treatment, OR by the presence of rimmed vacuoles in muscle biopsies [37].

Another limitation was the low frequency of myositis-specific autoantibodies documented. Five myositis-specific autoantibodies were included: anti-Jo-1, anti-Mi-2, anti-SRP, anti-PL7 and anti-PL12 antibodies and all were strongly associated with IIM. However, only anti-Jo-1 autoantibody had a significant number of observations $(\mathrm{n}=1,062)$ to permit analyses and inclusion in the classification criteria. A future update of the EULAR/ACR classification criteria should include the more recently-identified myositis-specific autoantibodies [21,22], in addition to more patients with IMNM, ADM, hypomyopathic DM and juvenile cases other than JDM.

\section{Recommendations}

- $\quad$ Patients with pathognomonic skin rashes (heliotrope rash, Gottron's papules and/or Gottron's sign) of JDM or DM are accurately classified with the EULAR/ACR classification criteria without including muscle biopsy data. For 
patients without these skin manifestations muscle biopsy is recommended. For DM patients without muscle involvement a skin biopsy is recommended.

- The EULAR/ACR classification criteria provide a score and a corresponding probability of having IIM. Each probability displays a unique sensitivity and specificity. The best balance between sensitivity and specificity can be found for a probability of $55-60 \%$ (total aggregated score of 25.5 and $\leq 5.7$ ) for the criteria not including muscle biopsy data, and 55-75\% (total aggregated score $\Varangle 6.7$ and $\leq$ 7.6) when including muscle biopsies. These cases are designated "probable IIM". The recommended cutoff needed for classifying a patient as IIM is $255 \%$.

- "Definite IIM" corresponds to a probability of $\$ 90 \%$ or a total aggregate score of 7.5 or more without muscle biopsy and 8.7 with muscle biopsy, and is recommended in studies where a high specificity is required.

- A patient is termed "possible IIM" if the probability is $250 \%$ and $<55 \%$ (a minimum score of 5.3 without biopsies and 6.5 with biopsies).

- For clarity and transparency, both the descriptive term ("possible", "probable" or "definite") and the probability and the aggregated score should be reported in studies.

\title{
Conclusions
}

New classification criteria for IIM and the major IIM subgroups have been developed. These data-driven criteria have a good feasibility, high sensitivity and specificity, have been partly validated in external cohorts, and are superior to previous criteria in capturing different subgroups of IIM. Revision of the criteria in the future will be important when additional validated myositis autoantibody tests, imaging and other tests are available in more IIM cases and comparator cases without IIM.

\section{Supplementary Material}

Refer to Web version on PubMed Central for supplementary material.

\section{Acknowledgments}

We thank Elin Forslund for assistance with data registration. We thank Drs. Andrew Mammen and Mike Ward for critical reading of the manuscript. The views expressed in this article are those of the authors and do not necessarily reflect the position or policy of the Department of Veterans Affairs or the United States government, or the NHS, the National Institute for Health Research or the Department of Health (UK).

\begin{abstract}
This criteria set has been approved by the European League Against Rheumatism (EULAR) Executive Committee and the American College of Rheumatology (ACR) Board of Directors as Provisional. This signifies that the criteria set has been quantitatively validated using patient data, but it has not undergone full validation based on an independent data set, using both cases and controls. This validation step is still needed before the criteria are fully validated.
\end{abstract}

Support

Financial support came from the European League Against Rheumatism (EULAR), American College of Rheumatology (ACR), The Myositis Association (TMA), and in part by the Intramural Research Program of the $\mathrm{NIH}$, National Institute of Environmental Health Sciences. 
Support was also obtained from the American Academy of Neurology (AAN), the Childhood Arthritis and Rheumatology Research Alliance (CARRA, CARRA Inc. is. funded by NIH-NIAMS), Friends of CARRA, and the Arthritis Foundation, the European Neuromuscular Centre (ENMC), the International Myositis Assessment and Clinical Studies Group (IMACS), the Muscle Study Group (MSG), the Rheumatologic Dermatology Society (RDS), the Pediatric Rheumatology European Society (PReS) network for JDM and the Pediatric Rheumatology International Trials Organization (PRINTO), and the European Science Foundation for the Euromyositis Register

\section{Funding}

Financial support came from the EULAR, ACR, TMA, and in part by the Intramural Research Program of the NIH, National Institute of Environmental Health Sciences.

\section{Competing interest}

JAS has received research grants from Takeda and Savient and consultant fees from Savient, Takeda, Regeneron, Merz, Bioiberica, Crealta and Allergan. JAS serves as the principal investigator for an investigator-initiated study funded by Horizon pharmaceuticals through a grant to DINORA, Inc., a 501 (c)(3) entity. JAS is a member of the executive of OMERACT, an organization that develops outcome measures in rheumatology and receives armslength funding from 36 companies; a member of the American College of Rheumatology's (ACR) Annual Meeting Planning Committee (AMPC); Chair of the ACR Meet-the-Professor, Workshop and Study Group Subcommittee; and a member of the Veterans Affairs Rheumatology Field Advisory Committee. HC and RGC's work in myositis is partly funded by grants from Arthritis Research UK (18474) and the Medical Research Council (MR/ N003322/1). JV's work in myositis is supported by Project (Ministry of Health, Czech Republic) for conceptual development of research organization 00023728.

\section{Appendix}

We are grateful for contribution of clinical data from investigators, and for participants contributing with valuable input at IMCCP meetings (See Appendix).

Working committee members

\begin{tabular}{|l|l|}
\hline Name & Affiliation \\
\hline Maria Amoruso & $\begin{array}{l}\text { Children's Hospital of Chicago and Northwestern University Feinberg School of } \\
\text { Medicine, Chicago, USA }\end{array}$ \\
\hline Helena Andersson & Section of Rheumatology, Oslo University Hospital-Rikshospitalet, Oslo, Norway \\
\hline Nastaran Bayat & $\begin{array}{l}\text { Environmental Autoimmunity Group, Clinical Research Branch, National Institute of } \\
\text { Environmental Health Sciences, National Institutes of Health, US Department of } \\
\text { Health and Human Services, Bethesda, USA }\end{array}$ \\
\hline Kavish J Bhansing & $\begin{array}{l}\text { Department of Neurology, Radboud University Medical Center, Nijmegen, The } \\
\text { Netherlands }\end{array}$ \\
\hline Richard Champbell & King's College Hospital, London, UK \\
\hline Christina Charles-Schoeman & $\begin{array}{l}\text { Division of Rheumatology, Department of Medicine, University of California Los } \\
\text { Angeles, Los Angeles, USA }\end{array}$ \\
\hline Vinay Chaudhry & $\begin{array}{l}\text { Department of Neurology, Johns Hopkins University School of Medicine, Baltimore, } \\
\text { USA }\end{array}$ \\
\hline Lisa Christopher-Stine & $\begin{array}{l}\text { Division of Rheumatology, Johns Hopkins University School of Medicine, Baltimore, } \\
\text { USA }\end{array}$ \\
\hline Lorinda Chung & $\begin{array}{l}\text { Department of Dermatology, Stanford University School of Medicine, Stanford, } \\
\text { USA; Division of Rheumatology, Palo Alto Veterans Affairs Health Care System, } \\
\text { Palo Alto, USA; Department of Medicine, Division of Rheumatology, Stanford } \\
\text { University School of Medicine, Stanford, USA }\end{array}$ \\
\hline Rheumatology Division, Medical College of Wisconsin, Milwaukee, USA \\
\hline Mary Cronin & The Myositis Association, 1940 Duke Street, Suite 200, Alexandria, USA \\
\hline Theresa Curry & Department of Neurology, Örebro University, Örebro, Sweden \\
\hline Kathe Dahlbom &
\end{tabular}




\begin{tabular}{|c|c|}
\hline Name & Affiliation \\
\hline Oliver Distler & Division of Rheumatology, University Hospital Zurich, Zurich, Switzerland \\
\hline Petros Efthimiou & $\begin{array}{l}\text { New York Methodist Hospital, Brooklyn, NY \& Weill Cornell Medical College, New } \\
\text { York, USA }\end{array}$ \\
\hline Baziel GM van Engelen & $\begin{array}{l}\text { Department of Neurology, Radboud University Medical Center, Nijmegen, The } \\
\text { Netherlands }\end{array}$ \\
\hline Abdullah Faiq & $\begin{array}{l}\text { Environmental Autoimmunity Group, Clinical Research Branch, National Institute of } \\
\text { Environmental Health Sciences, National Institutes of Health, US Department of } \\
\text { Health and Human Services, Bethesda, USA }\end{array}$ \\
\hline Payam Noroozi Farhadi & $\begin{array}{l}\text { Environmental Autoimmunity Group, Clinical Research Branch, National Institute of } \\
\text { Environmental Health Sciences, National Institutes of Health, US Department of } \\
\text { Health and Human Services, Bethesda, USA }\end{array}$ \\
\hline David Fiorentino & $\begin{array}{l}\text { Division of Immunology and Rheumatology, Stanford University School of Medicine, } \\
\text { Standford, USA }\end{array}$ \\
\hline Gerald Hengstman & Department of Neurology, Catharina Hospital, Eindhoven, the Netherlands \\
\hline Jessica Hoogendijk & $\begin{array}{l}\text { Rudolf Magnus Institute for Neuroscience, Department of Neurology, University } \\
\text { Medical Center Utrecht, Netherlands }\end{array}$ \\
\hline Adam Huber & $\begin{array}{l}\text { Pediatric Rheumatology, IWK Health Centre and Dalhousie University, Halifax, } \\
\text { Canada }\end{array}$ \\
\hline Hiroshi Kataoka & $\begin{array}{l}\text { Department of Medicine II, Hokkaido University Graduate School of Medicine, } \\
\text { Hokkaido, Japan }\end{array}$ \\
\hline Yasuhiro Katsumata & Institute of Rheumatology, Tokyo Women's Medical University, Tokyo, Japan \\
\hline Susan Kim & Boston Children`s Hospital, Pediatric Rheumatology, Boston, USA \\
\hline Michelle Kong-Rosario & $\begin{array}{l}\text { Division of Rheumatology, Northwell Health (formerly known as North Shore-LIJ } \\
\text { Health Systems), New York, USA }\end{array}$ \\
\hline Apostolos Kontzias & $\begin{array}{l}\text { Lerner College of Medicine, Case Western Reserve University, Adult } \\
\text { Autoinflammatory Clinic, Cleveland clinic, Cleveland, USA }\end{array}$ \\
\hline Petra Krol & $\begin{array}{l}\text { Department of Pediatrics and Adolescent Medicine, Charles University, 1st Medical } \\
\text { School, Prague, Czech Republic }\end{array}$ \\
\hline Takashi Kurita & $\begin{array}{l}\text { Department of Medicine II, Hokkaido University Graduate School of Medicine, } \\
\text { Hokkaido, Japan }\end{array}$ \\
\hline Zhan-Guo Li & $\begin{array}{l}\text { Department of Rheumatology and Immunology, People's Hospital of Beijing } \\
\text { University, China }\end{array}$ \\
\hline Björn Lindvall & Department of Neurology, Örebro University, Örebro, Sweden \\
\hline Helen Linklater & $\begin{array}{l}\text { Department of Rheumatology, King`s College Hospital NHS Foundation Trust, } \\
\text { London, UK }\end{array}$ \\
\hline Sara Magnusson-Bucher & Department of Rheumatology, Örebro University, Örebro, Sweden \\
\hline Sue Maillard & $\begin{array}{l}\text { Department of Rheumatology, Great Ormond Street Hospital for Children NHS Trust, } \\
\text { London, UK }\end{array}$ \\
\hline Gulnara Mamyrova & $\begin{array}{l}\text { Myositis Center, Division of Rheumatology, Department of Medicine, George } \\
\text { Washington University, Washington DC, USA }\end{array}$ \\
\hline Renato Mantegazza & $\begin{array}{l}\text { Neurology IV, Neuroimmunology and Neuromuscular Diseases Unit, Fondazione } \\
\text { Istituto Neurologico Carlo Besta, Milan, Italy }\end{array}$ \\
\hline Galina S Marder & $\begin{array}{l}\text { The Inflammatory Muscle Disease and Vasculitis Center, Hofstra Northwell School } \\
\text { of Medicine, Northwell Health, New York, USA }\end{array}$ \\
\hline Suely Kazue Nagahashi Marie & $\begin{array}{l}\text { Division of Neurology, Faculdade de Medicina, Universidade de São Paulo, São } \\
\text { Paulo, Brasil }\end{array}$ \\
\hline Pernille Mathiesen & Paediatric Department, Copenhagen University Hospital Holbaek, Holbaek, Denmark \\
\hline Clio P Mavragani & $\begin{array}{l}\text { Department of Pathophysiology, School of Medicine, University of Athens, Athens, } \\
\text { Greece }\end{array}$ \\
\hline Neil J McHugh & Royal National Hospital for Rheumatic Diseases, Bath, UK \\
\hline
\end{tabular}

Ann Rheum Dis. Author manuscript; available in PMC 2018 December 01. 


\begin{tabular}{|c|c|}
\hline Name & Affiliation \\
\hline Mimi Michaels & Department of Neurology, University of Kansas Medical Center, Kansas City, USA \\
\hline Reem Mohammed & $\begin{array}{l}\text { Division of Rheumatology, Department of Paediatrics, University of Toronto and The } \\
\text { Hospital for Sick Children, Toronto, Canada }\end{array}$ \\
\hline Gabrielle Morgan & $\begin{array}{l}\text { Children's Hospital of Chicago and Northwestern University Feinberg School of } \\
\text { Medicine, Chicago, USA }\end{array}$ \\
\hline David W Moser & Rheumatology, Cincinnati Children's Hospital Medical Center, Cincinnati, USA \\
\hline Haralampos M Moutsopoulos & $\begin{array}{l}\text { Department of Pathophysiology, School of Medicine, University of Athens, Athens, } \\
\text { Greece }\end{array}$ \\
\hline Lauren Pachman & $\begin{array}{l}\text { Lurie Children's Hospital and Northwestern University Feinberg School of Medicine, } \\
\text { Chicago, USA }\end{array}$ \\
\hline Harald E Paulus & $\begin{array}{l}\text { Department of Medicine, Division of Rheumatology, University of California at Los } \\
\text { Angeles, Los Angeles, USA }\end{array}$ \\
\hline Olga Petryna & $\begin{array}{l}\text { Mount Sinai Beth Israel Medical Center, NY, NY \& Icahn School of Medicine at } \\
\text { Mount Sinai, New York, USA }\end{array}$ \\
\hline Nicolo Pipitone & $\begin{array}{l}\text { Rheumatology Unit, Department of Internal Medicine, ASMN Hospital, Institute of } \\
\text { Hospitalization and Scientific Care, Reggio Emilia, Italy }\end{array}$ \\
\hline Andrea Ponyi & 2nd Dept. of Pediatrics, Semmelweis University, Budapest, Hungary \\
\hline Faisal Raja & Department of Neurology, University of Kansas Medical Center, Kansas City, USA \\
\hline Suzanne Ramsey & $\begin{array}{l}\text { Pediatric Rheumatology, IWK Health Centre and Dalhousie University, Halifax, } \\
\text { Canada }\end{array}$ \\
\hline Angello Ravelli & Pediatria II, Istituto Giannina Gaslini, Genoa, Italy \\
\hline P. van Riel & $\begin{array}{l}\text { Department of Neurology, Radboud University Medical Center, Nijmegen, The } \\
\text { Netherlands }\end{array}$ \\
\hline Gabriela Romo-Aguiñaga & $\begin{array}{l}\text { Department of Immunology and Rheumatology, Hospital General de Occidente and } \\
\text { University of Guadalajara, Guadalajara, Jalisco, México. }\end{array}$ \\
\hline Michael Rose & King's College Hospital, University of London, London UK \\
\hline Annet van Royen-Kerkhof & $\begin{array}{l}\text { Laboratory of Translational Immunology, Department of Pediatric Immunology, } \\
\text { University Medical Centre Utrecht, Utrecht, Netherlands }\end{array}$ \\
\hline Adriana Maluf Elias Sallum & $\begin{array}{l}\text { Pediatric Rheumatic Unit, Pediatric Department, Faculdade de Medicina, } \\
\text { Universidade de São Paulo, São Paulo, Brazil }\end{array}$ \\
\hline Samuel Katsuyuki Shinjo & $\begin{array}{l}\text { Division of Rheumatology, Faculdade de Medicina, Universidade de São Paulo, São } \\
\text { Paulo, Brazil }\end{array}$ \\
\hline Clovis Artur Almeida da Silva & $\begin{array}{l}\text { Pediatric Rheumatic Unit, Pediatric Department, Faculdade de Medicina, } \\
\text { Universidade de São Paulo, São Paulo, Brazil }\end{array}$ \\
\hline Sally Smith & $\begin{array}{l}\text { Department of Rheumatology, Great Ormond Street Hospital for Children NHS Trust, } \\
\text { London, UK }\end{array}$ \\
\hline Sarah Smith & Royal National Hospital for Rheumatic Diseases, Bath, UK \\
\hline Richard Sontheimer & $\begin{array}{l}\text { Department of Dermatology, University of Utah School of Medicine, Salt Lake City, } \\
\text { USA }\end{array}$ \\
\hline Elizabeth Stringer & $\begin{array}{l}\text { Pediatric Rheumatology, IWK Health Centre and Dalhousie University, Halifax, } \\
\text { Canada }\end{array}$ \\
\hline Heather Struck & Division of Rheumatology, Cedars Sinai Medical Center, Los Angeles, USA \\
\hline Katarzyna Świerkocka & $\begin{array}{l}\text { Connective Tissue Diseases Department, National Institute of Geriatrics, } \\
\text { Rheumatology and Rehabilitation, Warsaw, Poland }\end{array}$ \\
\hline Sarah L Tansley & Royal National Hospital for Rheumatic Diseases, Bath, UK \\
\hline Ira N Targoff & $\begin{array}{l}\text { VAMC, University of Oklahoma Health Sciences Center, and Oklahoma Medical } \\
\text { Research Foundation, Oklahoma City, USA }\end{array}$ \\
\hline Anne Tournadre & Service de rhumatologie, Hôpital G, Montpiad, France \\
\hline
\end{tabular}

Ann Rheum Dis. Author manuscript; available in PMC 2018 December 01. 


\begin{tabular}{|l|l|}
\hline Name & Affiliation \\
\hline Swamy Venuturupalli & Division of Rheumatology, Cedars Sinai Medical Center, Los Angeles, USA \\
\hline MC Vonk & $\begin{array}{l}\text { Department of Neurology, Radboud University Medical Center, Nijmegen, The } \\
\text { Netherlands }\end{array}$ \\
\hline Aleasha Warner & $\begin{array}{l}\text { Pediatric Rheumatology, IWK Health Centre and Dalhousie University, Halifax, } \\
\text { Canada }\end{array}$ \\
\hline Maria Winzer & $\begin{array}{l}\text { Division of Rheumatology, Department of Medicine III, University Center Carl } \\
\text { Gustav Carus, Technical University of Dresden, Dresden, Germany }\end{array}$ \\
\hline Robert Wortmann & $\begin{array}{l}\text { Rheumatology Section, Geisel School of Medicine at Dartmouth, One Medical } \\
\text { Center Drive, Lebanon, USA }\end{array}$ \\
\hline Mina Yassaee & $\begin{array}{l}\text { Department of Dermatology, Philadelphia VAMC and Hospital of the University of } \\
\text { Pennsylvania, Philadelphia, USA }\end{array}$ \\
\hline
\end{tabular}

\section{References}

1. Plotz PH, Rider GL, Targoff IN, et al. NIH conference. Myositis: immunologic contributions to understanding cause, pathogenesis, and therapy. Ann Intern Med. 1995; 122:715-24. [PubMed: 7702234]

2. Dalakas MC. Inflammatory muscle diseases. N Eng J Med. 2015; 372:1734-47.

3. Rider LG, Giannini EH, Brunner HI, et al. International Myositis Assessment and Clinical Studies Group. International consensus on preliminary definitions of improvement in adult and juvenile myositis. Arthritis Rheum. 2004; 50:2281-90. [PubMed: 15248228]

4. Oddis CV, Rider LG, Reed AM, et al. International consensus guidelines for trials of therapies in the idiopathic inflammatory myopathies. Arthritis Rheum. 2005; 52:2607-15. [PubMed: 16142757]

5. Medsger TA Jr, Dawson WN Jr, Masi AT. The epidemiology of polymyositis. Am J Med. 1970; 48:715-23. [PubMed: 5420557]

6. DeVere R, Bradley WG. Polymyositis: its presentation, morbidity and mortality. Brain. 1975; 98:637-66. [PubMed: 1218371]

7. Bohan A, Peter JB. Polymyositis and dermatomyositis (First of two parts). N Engl J Med. 1975; 292:344-7. [PubMed: 1090839]

8. Bohan A, Peter JB. Polymyositis and dermatomyositis (Second of two parts). N Engl J Med. 1975; 292:403-7. [PubMed: 1089199]

9. Griggs RC, Askanas V, DiMauro S, et al. Inclusion body myositis and myopathies. Ann Neurol. 1995; 38:705-13. [PubMed: 7486861]

10. Tanimoto K, Nakano K, Kano S, et al. Classification criteria for polymyositis and dermatomyositis. J Rheumatol. 1995; 22:668-74. [PubMed: 7791161]

11. Targoff IN, Miller FW, Medsger TA, et al. Classification criteria for the idiopathic inflammatory myopathies. Curr Opin Rheumatol. 1997; 9:527-35. [PubMed: 9375282]

12. Mastaglia FL, Phillips BA. Idiopathic inflammatory myopathies: epidemiology, classification and diagnostic criteria. Rheum Dis Clin North Am. 2002; 28:723-41. [PubMed: 12510664]

13. van der Meulen MF, Bronner IM, Hoogendijk JE, et al. Polymyositis: an overdiagnosed entity. Neurology. 2003; 61:316-21. [PubMed: 12913190]

14. Dalakas M, Hohlfeld R. Polymyositis and dermatomyositis. Lancet. 2003; 362:971-982. [PubMed: 14511932]

15. Hoogendijk JE, Amato AA, Lecky BR, et al. 119th ENMC international workshop: trial design in adult idiopathic inflammatory myopathies, with the exception of inclusion body myositis, 10-12 October 2003, Naarden, The Netherlands. Neuromuscul Disord. 2004; 14:337-45. [PubMed: 15099594]

16. Troyanov Y, Targoff IN, Tremblay JL, et al. Novel classification of idiopathic inflammatory myopathies based on overlap syndrome features and autoantibodies: analysis of 100 French Canadian patients. Medicine. 2005; 84:231-49. [PubMed: 16010208] 
17. Miller FW, Rider LG, Plotz PH, et al. Polymyositis: an overdiagnosed entity. Neurology. 2004; 63:402.

18. Bradley WG. Polymyositis: an overdiagnosed entity. Neurology. 2004; 63:402.

19. Hengstman GJ, van Engelen BG. Polymyositis: an overdiagnosed entity. Neurology. 2004; 63:4023.

20. Engel AG, Arahata K. Mononuclear cells in myopathies: Quantitation of functionally distinct subsets, recognition of antigen-specific cell-mediated cytotoxicity in some diseases, and implications for the pathogenesis of the different inflammatory myopathies. Hum Pathol. 1986; 17:704-21. [PubMed: 3459704]

21. Betteridge Z, McHugh N. Myositis-specific autoantibodies: an important tool to support diagnosis of myositis. J Intern Med. 2016; 280:8-23. [PubMed: 26602539]

22. Rider LG, Nistala K. The juvenile idiopathic inflammatory myopathies: pathogenesis, clinical and autoantibody phenotypes, and outcomes. J Intern Med. 2016; 280:24-38. [PubMed: 27028907]

23. Love LA, Leff RL, Fraser DD, et al. A new approach to the classification of idiopathic inflammatory myopathy: Myositis-specific autoantibodies define useful homogeneous patient groups. Medicine (Baltimore). 1991; 70:360-74. [PubMed: 1659647]

24. Singh JA, Solomon DH, Dougados M, et al. Development of classification and response criteria for rheumatic diseases. Arthritis Rheum. 2006; 55:348-52. [PubMed: 16739201]

25. Dougados M, Gossec L. Classification criteria for rheumatic diseases: why and how? Arthritis Rheum. 2007; 57:1112-5. [PubMed: 17907226]

26. Van de Ven AH, Delbecq AL. The Effectiveness of Nominal, Delphi, and Interacting Group Decision Making Processes. Acad Manage J. 1974; 17:605-21.

27. Fink A, Kosecoff J, Chassin M, et al. Consensus Methods: Characteristics and Guidelines for Use. Am J Public Health. 1984; 74:979-83. [PubMed: 6380323]

28. Ruperto N, Meiorin S, Iusan SM, et al. Consensus procedures and their role in pediatric rheumatology. Curr Rheumatol Rep. 2008; 10:142-6. [PubMed: 18460270]

29. Totikidis V. Applying the Nominal Group Technique (NGT) in Community Based Action Research for Health Promotion and Disease Prevention. The Australian Community Psychologist. 2010; 22:18-29.

30. ARA Glossary Committee. Dictionary of the Rheumatic Diseases 1982; Vol I: Signs and Symptoms [monograph]. New York, NY: Contact Associates International Ltd.;

31. ARA Glossary Committee. Dictionary of the Rheumatic Diseases 1985; Vol II: Diagnostic Testing [monograph]. New York, NY: Contact Associates International Ltd.;

32. Efron B, Tibshirani RJ. Improvements on Cross-Validation: The 632+ Bootstrap Method. J Am Stat Assoc. 1997; 92:548-60.

33. Hsiung SH, Chan EF, Elenitsas R, et al. Multicentric reticulohistiocytosis presenting with clinical features of dermatomyositis. J Am Acad Dermatol. 2003; 48(2 Suppl):S11-4. [PubMed: 12582374]

34. Fett N, Liu RH. Multicentric reticulohistiocytosis with dermatomyositis-like features: a more common disease presentation than previously thought. Dermatology. 2011; 222:102-8. [PubMed: 21252485]

35. Aggarwal R, Ringold S, Khanna D, et al. Distinctions between diagnostic and classification criteria? Arthritis Care Res (Hoboken). 2015; 67:891-7. [PubMed: 25776731]

36. Casciola-Rosen L, Mammen AL. Myositis autoantibodies. Curr Opin Rheumatol. 2012; 24:602-8. [PubMed: 22955022]

37. Lloyd TE, Mammen AL, Amato AA, et al. Evaluation and construction of diagnostic criteria for inclusion body myositis. Neurology. 2014; 83:426-33. [PubMed: 24975859] 


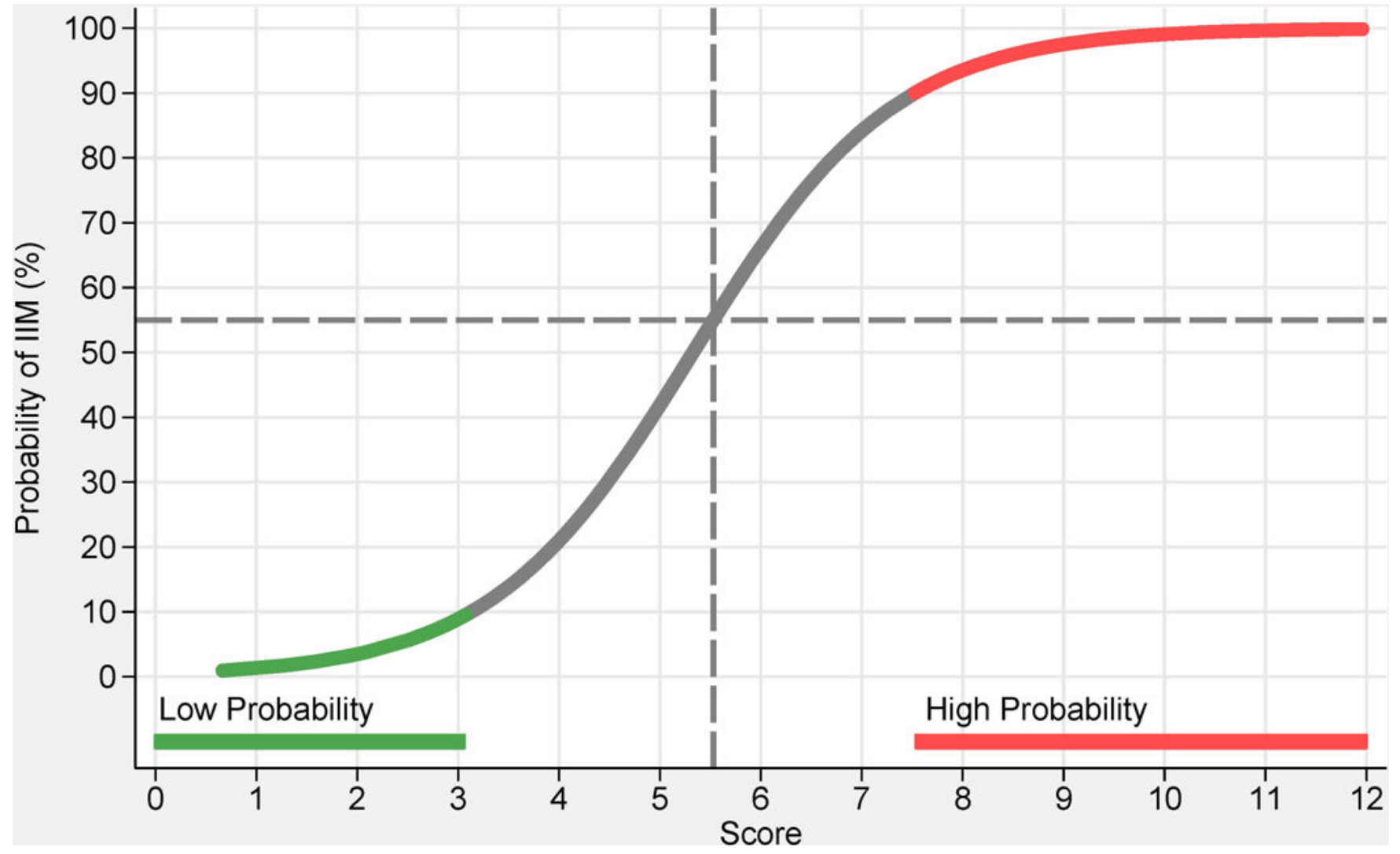




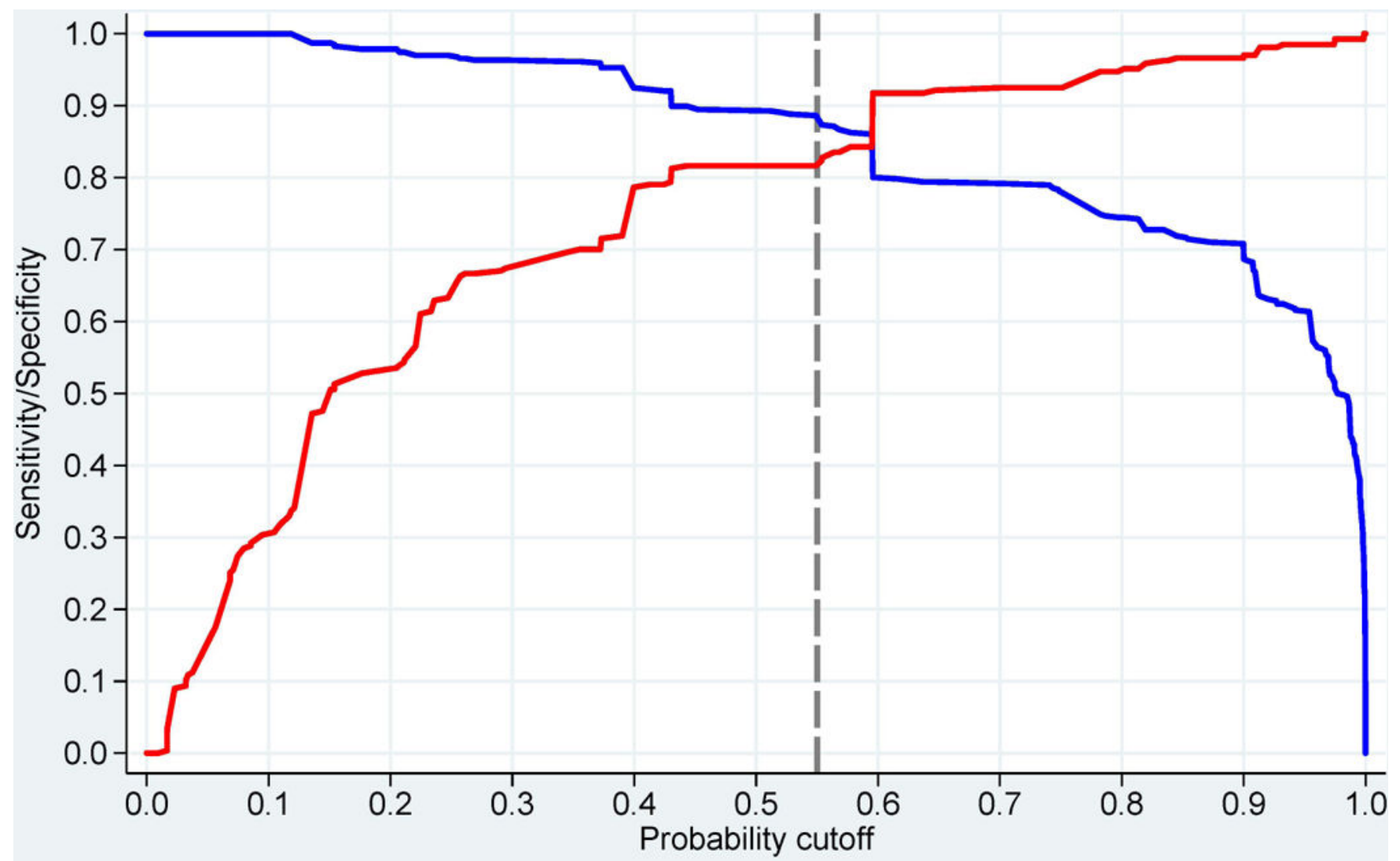




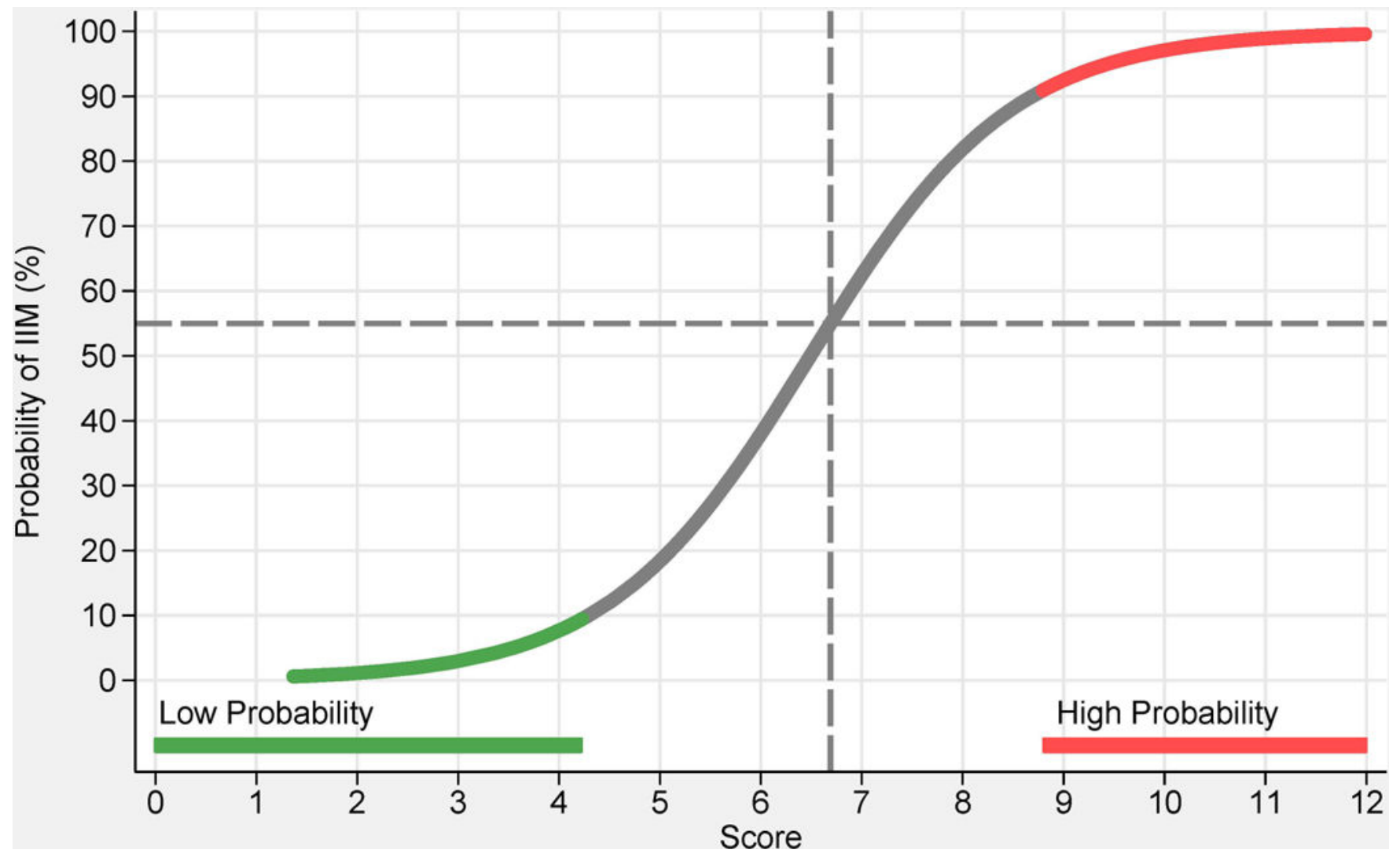




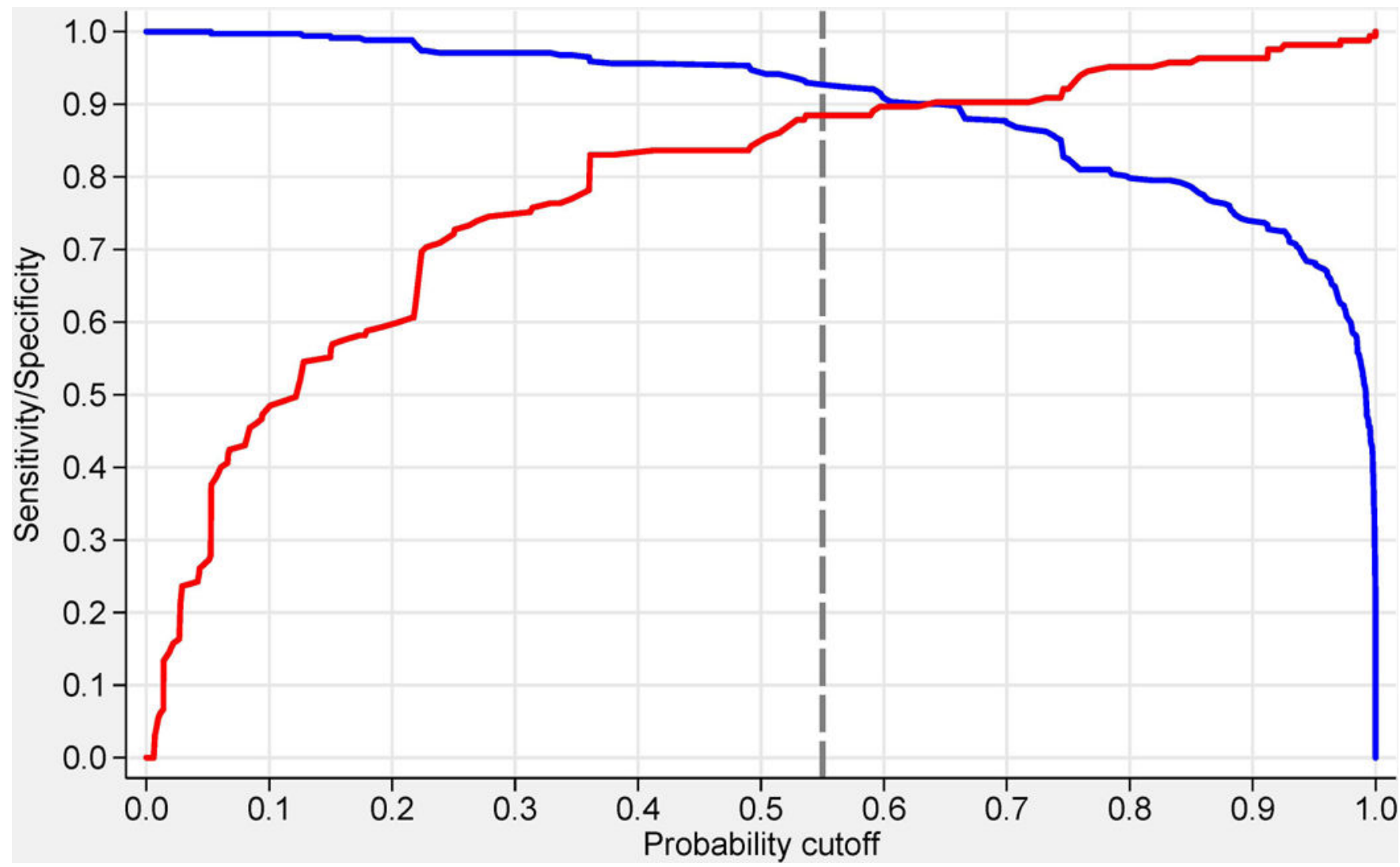

Figure 1.

Probability of having idiopathic inflammatory myopathies (IIM) based on the EULAR/ACR classification criteria for IIM. Each score obtained from the classification criteria corresponds to a probability of having the disease, without muscle biopsy data (A), or with muscle biopsy data (B). Each score and probability of disease display a unique set of sensitivity (blue line) and specificity (red line) measurements for the classification criteria not including muscle biopsy data (C) or including muscle biopsy data (D). The most optimal point of accuracy should be stated in publications and be appropriate to the intended purpose, with the recommendation of using a minimum of $55 \%$ probability (score of 5.5 without biopsies; 6.7 with biopsies) for classifying a case as IIM ("probable IIM") (dotted line). "Definite IIM" corresponds to a probability of at least $90 \%$ (score of 7.5 without biopsies; 8.7 with biopsies). 


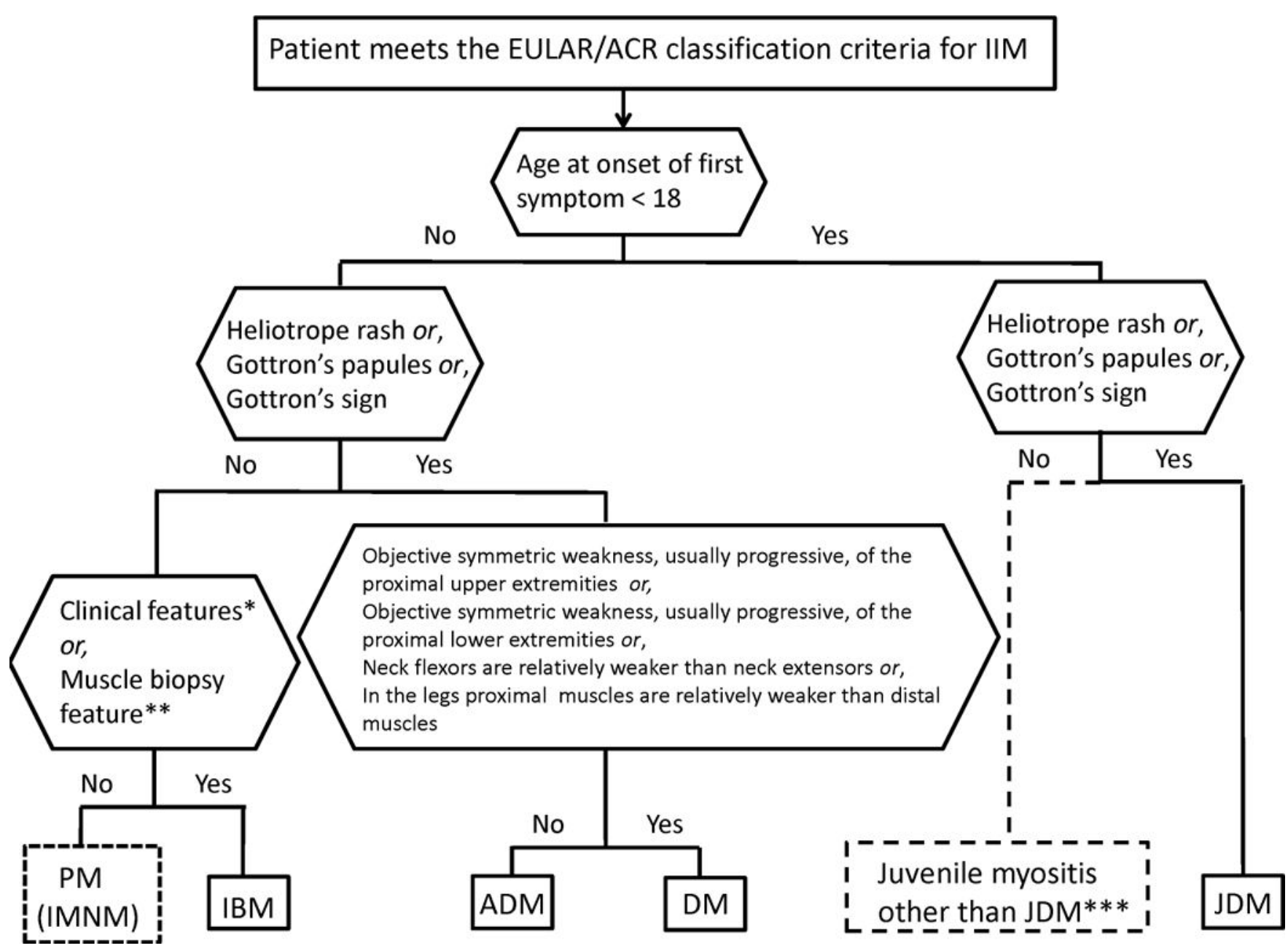

Figure 2.

Classification tree for subgroups of idiopathic inflammatory myopathies (IIM). A patient must first meet the EULAR/ACR classification criteria for IIM (probability of IIM $255 \%$ ).

The patient can then be sub-classified using the classification tree. The subgroup of PM patients includes patients with immune-mediated necrotizing myopathy (IMNM). For IBM classification one of the following, *Finger flexor weakness and response to treatment: not improved, or **Muscle biopsy: rimmed vacuoles, is required for diagnosis. ***Juvenile myositis other than JDM was developed based on expert opinion. IMNM and hypomyopathic DM were too few to allow sub-classification.

PM, polymyositis; IMNM, immune-mediated necrotizing myopathy; IBM, inclusion body myositis; ADM, amyopathic dermatomyositis; DM, dermatomyositis; JDM, juvenile dermatomyositis. 
Table 1

Demographic data of the International Myositis Classification Criteria Project cohort

\begin{tabular}{|c|c|c|}
\hline & $\underset{(\mathbf{n}=976)}{\operatorname{IIM}}$ & $\underset{(n=624)}{\text { Comparators }}$ \\
\hline \multicolumn{3}{|l|}{ Sex, n (\%) } \\
\hline Female & $652(66.8)$ & $369(59.1)$ \\
\hline Male & $324(33.2)$ & $255(40.9)$ \\
\hline Adult onset disease ${ }^{*}, \mathrm{n}(\%)$ & $727(74.5)$ & $509(81.6)$ \\
\hline Childhood onset disease ${ }^{*}, \mathrm{n}(\%)$ & $249(25.5)$ & $115(18.4)$ \\
\hline Age at onset of symptom, median (IQR), years & $44.0(14.7-57.0)$ & $41.0(20.0-56.0)$ \\
\hline Age at diagnosis, median (IQR), years & $45.5(16.2-59.3)$ & $45.0(25.8-58.0)$ \\
\hline Disease duration from time of first symptom ${ }^{\dagger}$, median (IQR), years & $4.0(2.0-8.0)$ & $4.0(1.0-9.0)$ \\
\hline Disease duration from time of diagnosis ${ }^{t}$, median (IQR), years & $3.0(1.0-6.0)$ & $1.8(0.0-4.5)$ \\
\hline \multicolumn{3}{|l|}{ Ethnicity, n (\%) } \\
\hline Caucasian & $611(62.6)$ & $360(57.7)$ \\
\hline Asian & $177(18.1)$ & $156(25.0)$ \\
\hline Hispanic & $51(5.2)$ & $25(4.0)$ \\
\hline African & $40(4.1)$ & $28(4.5)$ \\
\hline Native American & $18(1.8)$ & $4(0.6)$ \\
\hline Pacific Island & $3(0.3)$ & $1(0.2)$ \\
\hline Mixed & $37(3.8)$ & $22(3.5)$ \\
\hline Unknown & $54(5.5)$ & $32(5.1)$ \\
\hline \multicolumn{3}{|l|}{ Disease onset $\mathcal{\xi}, \mathrm{n}(\%)$} \\
\hline Acute (days to 2 weeks) & $45(4.6)$ & $64(10.3)$ \\
\hline Subacute ( $>2$ weeks to $\leq 2$ months) & $237(24.3)$ & $88(14.1)$ \\
\hline Insidious (> 2 months to years) & $648(66.4)$ & $444(71.2)$ \\
\hline NA & $46(4.7)$ & $28(4.5)$ \\
\hline \multicolumn{3}{|l|}{ Onset of first symptoms assumed to be related to the disease } \\
\hline \multicolumn{3}{|l|}{${ }^{t}$ Time from first symptom to last clinical evaluation } \\
\hline \multicolumn{3}{|l|}{ Time from diagnosis to last clinical evaluation } \\
\hline \multicolumn{3}{|c|}{$\xi_{\text {Onset and progression of the first symptoms of the syndrome to the full disease presentation }}$} \\
\hline
\end{tabular}

Ann Rheum Dis. Author manuscript; available in PMC 2018 December 01. 
Table 2

The EULAR/ACR classification criteria for adult and juvenile idiopathic inflammatory myopathies

\begin{tabular}{|c|c|c|c|}
\hline \multicolumn{4}{|c|}{ When no better explanation for the symptoms and signs exists these classification criteria can be used } \\
\hline \multirow[t]{2}{*}{ Variable } & \multicolumn{2}{|c|}{ Score Points } & \multirow{2}{*}{ Definition } \\
\hline & Without muscle biopsy & With muscle biopsy & \\
\hline \multicolumn{4}{|l|}{ Age of onset } \\
\hline $\begin{array}{l}\text { Age of onset of first symptom } \\
\text { assumed to be related to the disease } \geq \\
18 \text { years and }<40 \text { years }\end{array}$ & 1.3 & 1.5 & $\begin{array}{l}18 \leq \text { Age (years) at onset of first symptom } \\
\text { assumed to be related to the disease }<40\end{array}$ \\
\hline $\begin{array}{l}\text { Age of onset of first symptom } \\
\text { assumed to be related to the disease } \geq \\
40 \text { years }\end{array}$ & 2.1 & 2.2 & $\begin{array}{l}\text { Age (years) at onset of first symptom assumed to } \\
\text { be related to the disease } \geq 40\end{array}$ \\
\hline \multicolumn{4}{|l|}{ Muscle weakness } \\
\hline $\begin{array}{l}\text { Objective symmetric weakness, } \\
\text { usually progressive, of the proximal } \\
\text { upper extremities }\end{array}$ & 0.7 & 0.7 & $\begin{array}{l}\text { Weakness of proximal upper extremities as } \\
\text { defined by manual muscle testing or other } \\
\text { objective strength testing, which is present on } \\
\text { both sides and is usually progressive over time }\end{array}$ \\
\hline $\begin{array}{l}\text { Objective symmetric weakness, } \\
\text { usually progressive, of the proximal } \\
\text { lower extremities }\end{array}$ & 0.8 & 0.5 & $\begin{array}{l}\text { Weakness of proximal lower extremities as } \\
\text { defined by manual muscle testing or other } \\
\text { objective strength testing, which is present on } \\
\text { both sides and is usually progressive over time }\end{array}$ \\
\hline $\begin{array}{l}\text { Neck flexors are relatively weaker } \\
\text { than neck extensors }\end{array}$ & 1.9 & 1.6 & $\begin{array}{l}\text { Muscle grades for neck flexors are relatively } \\
\text { lower than neck extensors as defined by manual } \\
\text { muscle testing or other objective strength testing }\end{array}$ \\
\hline $\begin{array}{l}\text { In the legs proximal muscles are } \\
\text { relatively weaker than distal muscles }\end{array}$ & 0.9 & 1.2 & $\begin{array}{l}\text { Muscle grades for proximal muscles in the legs } \\
\text { are relatively lower than distal muscles in the } \\
\text { legs as defined by manual muscle testing or } \\
\text { other objective strength testing }\end{array}$ \\
\hline \multicolumn{4}{|l|}{ Skin manifestations } \\
\hline Heliotrope rash & 3.1 & 3.2 & $\begin{array}{l}\text { Purple, lilac-colored or erythematous patches } \\
\text { over the eyelids or in a periorbital distribution, } \\
\text { often associated with periorbital edema }\end{array}$ \\
\hline Gottron’s papules & 2.1 & 2.7 & $\begin{array}{l}\text { Erythematous to violaceous papules over the } \\
\text { extensor surfaces of joints, which are sometimes } \\
\text { scaly. May occur over the finger joints, elbows, } \\
\text { knees, malleoli and toes }\end{array}$ \\
\hline Gottron's sign & 3.3 & 3.7 & $\begin{array}{l}\text { Erythematous to violaceous macules over the } \\
\text { extensor surfaces of joints, which are not } \\
\text { palpable }\end{array}$ \\
\hline \multicolumn{4}{|l|}{ Other clinical manifestations } \\
\hline Dysphagia or esophageal dysmotility & 0.7 & 0.6 & $\begin{array}{l}\text { Difficulty in swallowing or objective evidence of } \\
\text { abnormal motility of the esophagus }\end{array}$ \\
\hline \multicolumn{4}{|l|}{ Laboratory measurements } \\
\hline $\begin{array}{l}\text { Anti-Jo-1 (anti-histidyl-tRNA } \\
\text { synthetase) autoantibody present }\end{array}$ & 3.9 & 3.8 & $\begin{array}{l}\text { Autoantibody test in serum performed with } \\
\text { standardized and validated test, showing positive } \\
\text { result }\end{array}$ \\
\hline $\begin{array}{l}\text { Elevated serum levels of creatine } \\
\text { kinase }(\mathrm{CK}){ }^{*} \text { or lactate } \\
\text { dehydrogenase }(\mathrm{LDH}){ }^{*} \text { or aspartate } \\
\text { aminotransferase (ASAT/AST/ } \\
\text { SGOT) }{ }^{*} \text { or } \text { alanine aminotransferase } \\
(\text { ALAT/ALT/SGPT) }\end{array}$ & 1.3 & 1.4 & $\begin{array}{l}\text { The most abnormal test values during the disease } \\
\text { course (highest absolute level of enzyme) above } \\
\text { the relevant upper limit of normal }\end{array}$ \\
\hline
\end{tabular}




\begin{tabular}{|l|c|c|l|}
\hline \multicolumn{1}{|l|}{ When no better explanation for the symptoms and signs exists these classification criteria can be used } \\
\hline Variable & \multicolumn{2}{|c|}{ Score Points } & Definition \\
\hline $\begin{array}{l}\text { Endomysial infiltration of } \\
\text { mononuclear cells surrounding, but } \\
\text { not invading, myofibres }\end{array}$ & Without muscle biopsy & With muscle biopsy & \\
\hline $\begin{array}{l}\text { Perimysial and/or perivascular } \\
\text { infiltration of mononuclear cells }\end{array}$ & 1.7 & $\begin{array}{l}\text { Muscle biopsy reveals endomysial mononuclear } \\
\text { cells abutting the sarcolemma of otherwise } \\
\text { healthy, non-necrotic muscle fibers, but there is } \\
\text { no clear invasion of the muscle fibers }\end{array}$ \\
\hline Perifascicular atrophy & 1.2 & $\begin{array}{l}\text { Mononuclear cells are located in the perimysium } \\
\text { and/or located around blood vessels (in either } \\
\text { perimysial or endomysial vessels) }\end{array}$ \\
\hline Rimmed vacuoles & 1.9 & $\begin{array}{l}\text { Muscle biopsy reveals several rows of muscle } \\
\text { fibers which are smaller in the perifascicular } \\
\text { region than fibers more centrally located }\end{array}$ \\
\hline
\end{tabular}

Serum levels above the upper limit of normal 


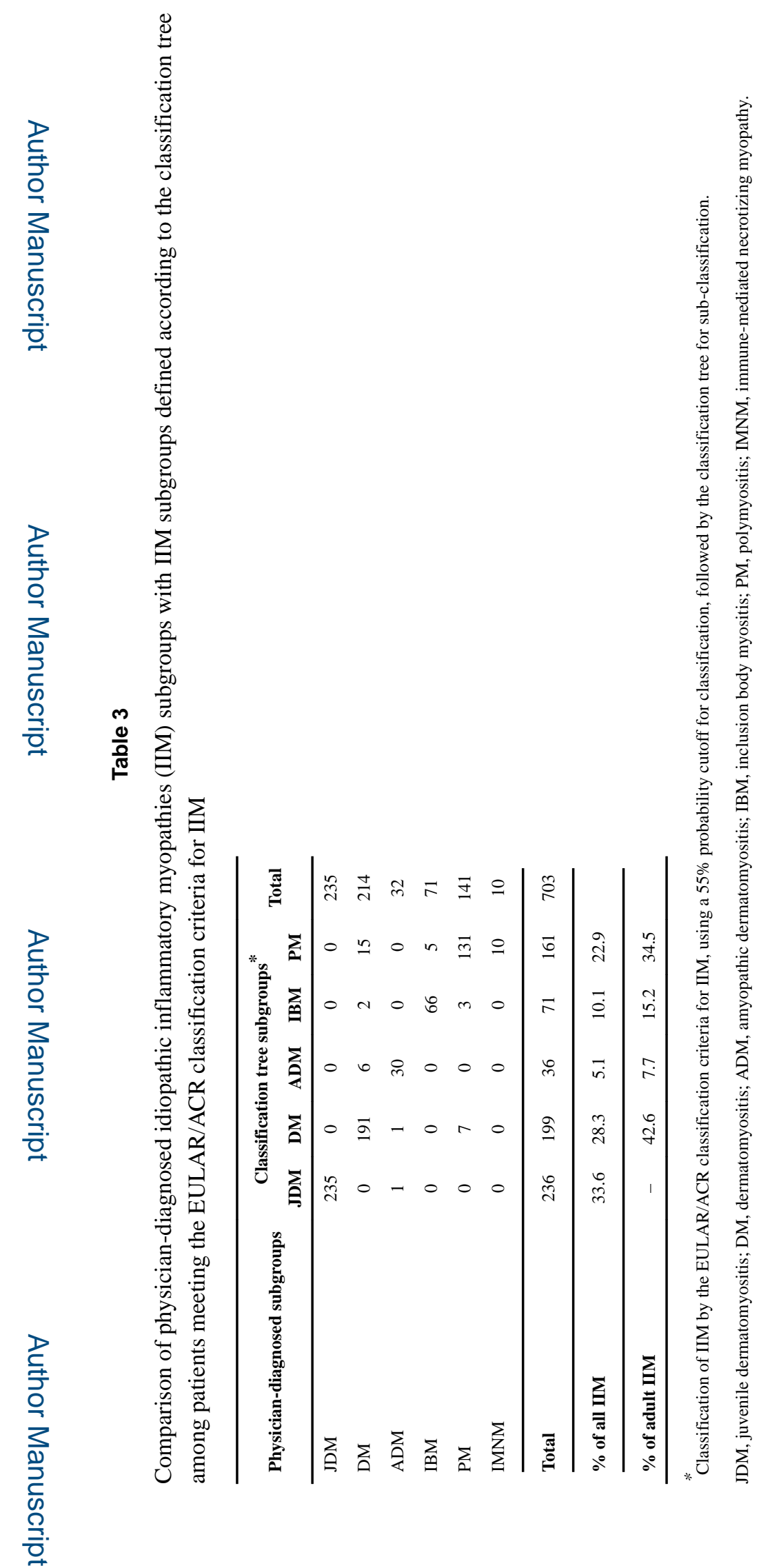

Ann Rheum Dis. Author manuscript; available in PMC 2018 December 01. 


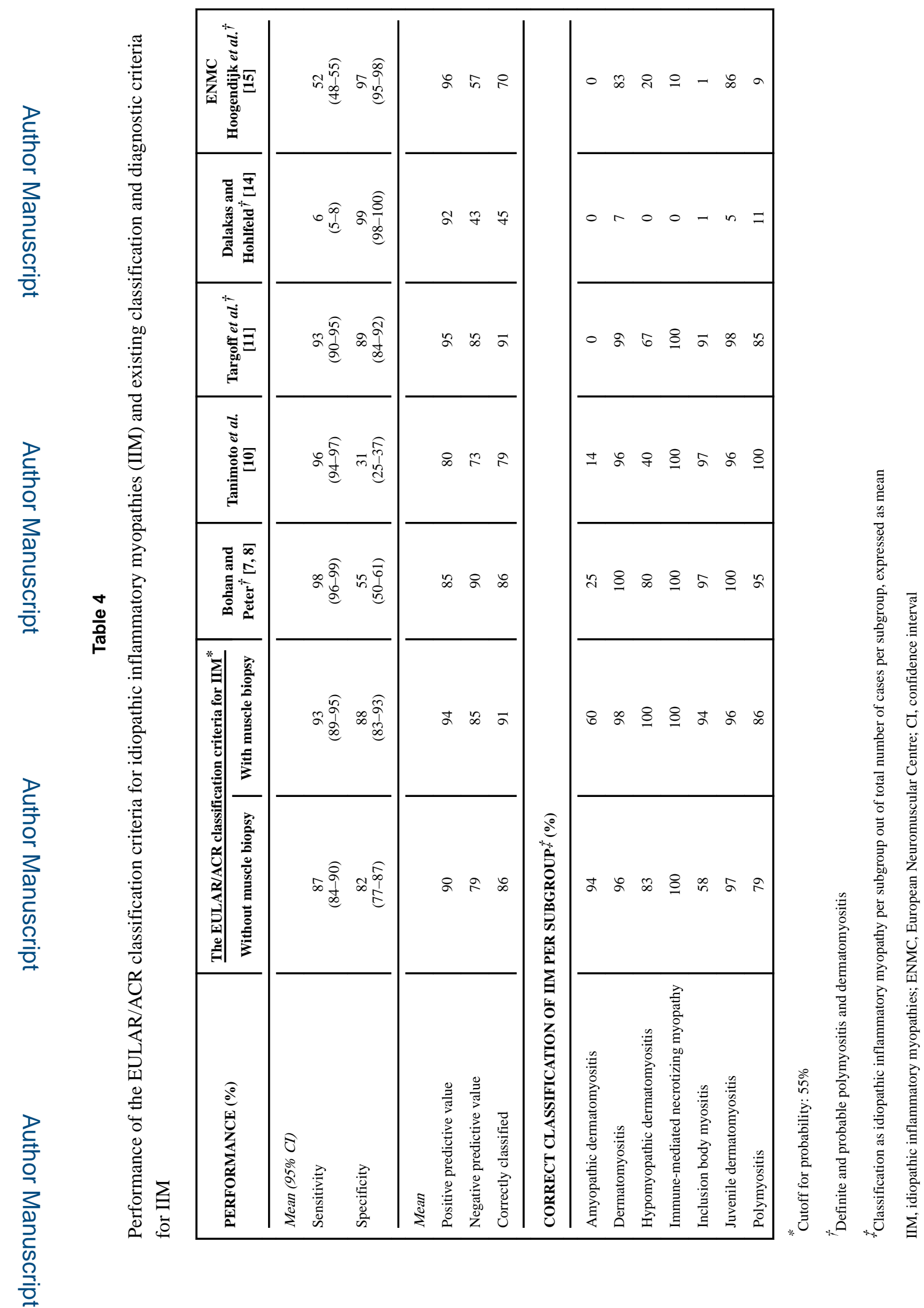

Ann Rheum Dis. Author manuscript; available in PMC 2018 December 01. 